\title{
O fio tênue e áspero da poesia de Ana Marques Gastão
}

\section{The coarse and tenuous thread of Ana Marques Gastão's poetry}

\author{
Claudia Amorim ${ }^{1}$
}

\section{Resumo}

O artigo propõe uma leitura crítica da obra da poeta Ana Marques Gastão, a partir da imagem da(s) mão(s), presente no processo da escrita e no exercício indagativo do sujeito em sua relação com o mundo. Dentro de tal proposta, consideramos também o diálogo com outras artes, como a música, a dança e a pintura.

Palavras-chave: Ana Marques Gastão. Poesia. Imagem. Diálogo interartes.

\begin{abstract}
This article proposes a critical reading of Ana Marques Gastão's poetry, starting from the image of hand (s) present in the writing processand inquisitive exercise of the subjectvis-a-vis the world. This proposal also considers the dialogue with other art forms, such as music, dance and painting.
\end{abstract}

Keywords: Ana Marques Gastão. Poetry. Image. Interart dialogue.

Tudo nos é dado, tudo e nada, invisíveis mãos.

É como tu, a noite (GASTÃO, 2002, p. 85).

O poema desfaz-se-me nas mãos, alvoroçadamente mudo, é excesso que levo comigo até deixar de o ver. Passo então a ver-me de fora: os versos morrem nas estrofes da memória.

Sou um túmulo de palavras, lâmina de dor (GASTÃO, 2008, p. 12).

Las cosas ocurrieron así. Teseo no podia saber que del otro lado del laberinto estaba el otro laberinto, el del tiempo y que en algún lugar prefijado estaba Medea.

El hilo se ha perdido; el laberinto se ha perdido también. Ahora ni siquiera sabemos si nos rodea un laberinto, un secreto cosmos, o un caos azaroso. Nuestro hermoso deber es imaginar que hay un laberinto e un hilo. Nunca daremos con el hilo; acaso lo encontramos y lo perdemos en un acto de fe, en una cadencia, en el sueño, en las palabras que se llaman

filosofia o en la mera y sencilla felicidad (BORGES, 2003, p. 477).

\footnotetext{
${ }^{1}$ Doutorado em Literatura Comparada pela Universidade do Estado do Rio de Janeiro (UERJ), Rio de Janeiro, Rio de Janeiro, Brasil. Professora Associada da Universidade do Estado do Rio de Janeiro, Rio de Janeiro, Rio de Janeiro, Brasil. E-mail: claudia.amorim@uol.com.br
} 
Em "El hilo de la fábula", Borges observa que, para adentrar na fábula, ou no sonho, há um fio que Teseu leva ao labirinto, o fio de Ariadne. Mas Teseu não sabe que o labirinto guarda outro labirinto, o labirinto do tempo, cujo fio se encontra e se perde. Por instantes, a sua perda é capaz de fazer-nos mirar o sonho, a filosofia ou a simples felicidade. Miragem e poesia. Poesia e miragem. Parece ter o poema essa capacidade da fábula que nos faz ver por instantes o sonho, a filosofia ou a simples felicidade.

Aventuro-me com alguma felicidade e igual medida de risco a usar as palavras para falar da poesia, para tentar capturar, como se fosse possível, a sua força sempre volátil. Entrego-me ao exercício de pensá-la criticamente, ainda que ela sempre nos escape, em sua realidade insubmissa.

Pensar a poética de um(a) poeta é tentar seguir algum caminho iluminado, um clarão na beleza da escuridão em que o poema reside, sem nunca se estar completamente certo de se poder tocar o seu fim. Ou é ainda entrar no labirinto, correndo-se o risco de se encontrar o fio e de se perdê-lo.

Imbuída desse ímpeto, a que a profissão e a experiência de leitora me autorizam, proponho-me a traçar algumas observações a partir do caminho trilhado por meio de um dos múltiplos fios-imagem na poesia de Ana Marques Gastão, entrada possível no labirinto de sua poesia.

No caleidoscópio de imagens da obra poética de Gastão, cristaliza-se, a meu ver, entre outras tantas imagens, a forte presença da mão ou das mãos, nunca completamente estáticas porque quase sempre instrumento da escrita, do movimento firme ou sutil, do gesto em direção a um vazio que se contorna, ou em direção a outro(a), a quem a escrita se dirige, e também ao(à) leitor(a) à espreita do gesto.

Ana Marques Gastão é poeta, crítica literária e ensaísta. Coordena a revista Colóquio Letras publicação da Fundação Calouste Gulbenkian -, dirigida pelo poeta Nuno Júdice, e divide o seu tempo entre a escrita artística e a ensaística, enquanto mantém com Júdice a regularidade cuidadosa da revista desde 2009. Estreia na poesia com o livro Tempo de
Morrer / Tempo para Viver (1998), a que se seguem Terra sem Mãe (2000), Três vezes Deus (2001), livro de poemas em coautoria com os poetas portugueses António Rego Chaves e Armando Silva Carvalho, Nocturnos (2002), Nós/Nudos - 25 poemas sobre 25 imagens de Paula Rego (2004), obra que lhe rendeu o Prêmio Pen Clube, Lápís Mínimo (2008), Adornos (2011), L de Lisboa (2015), O olho e a mão (2018), em coautoria com o poeta, ensaísta e professor brasileiro Sérgio Nazar David.

Além da obra artística, Ana Marques Gastão organizou o livro $O$ Falar dos Poetas (2011), no qual entrevista grandes poetas portugueses do final do século XX e início do XXI, e editou o volume de ensaios Ana Hatherly - Esperança e Desejo Aspectos do Pensamento Utópico Barroco (2016). $\mathrm{Na}$ escrita ensaística, é ainda de sua autoria o volume As Palavras Fracturadas, livro no qual discorre sobre a poesia e o fazer poético.

Seguindo o fio-imagem que me leva ao labirinto da obra poética de Ana Marques Gastão, percorrerei a reiterada imagem das mãos, que ora têm ofício sagrado de escrever, ora são instrumentos do gesto que instaura um movimento vital, ora são o contato tátil possível entre a poeta, que escreve o mundo, e o próprio mundo que a cerca. A mão - também como metonímia da própria escrita parece ser o campo de mediação da poeta ante o absurdo estupendo da existência, que a sua poesia parece trazer. Nesse breve estudo, deter-me-ei mais particularmente nas obras em que a imagem da mão ou das mãos parece ser mais recorrente, como em Nocturnos, Nós/Nudos, Lápis Mínimo, Adornos e $O$ olho e a mão.

A mão da poesia, a mão da poeta, a mão que cria arte. Não por acaso, a obra Nocturnos (2002), que apresenta uma aproximação poética com a música (mais especificamente com a composição para piano do compositor polonês Frédéric Chopin), estabelece um diálogo poético já em seu título com as mãos que se conjugam ao teclado. Também em Nós/Nudos - 25 poemas sobre 25 telas de Paula Rego, a mão se desdobra em escrita poética e diálogo apurado com outra mão, a que maneja os pincéis de que resultam imagens, reproduzidas no 
livro. Em outra obra poética, $O$ olho e a mão, em coautoria com Sérgio Nazar David, os olhos de ambos os poetas postos em telas dos mais variados pintores movem as mãos de ambos, em sintonia fina, em poemas-imagens pintados por palavras.

No contexto da criação, a poeta estabelece um diálogo interartes, trazendo para o cerne da criação poética a ideia de que "o poema transcende a linguagem" (PAZ, 1990, p. 48) porque "nascido da palavra, o poema desemboca em algo que a transpassa" (PAZ, 1990, p. 48). Nesse sentido, a mão, capaz de unir a escrita poética, a música materializada no instrumento e a tela resultante da pintura, traduz-se nesse exercício humano que conjuga, para usar o título do belo ensaio que abre As Palavras Fracturadas, "a cabeça, o corpo, a viagem".

Se a evocação às artes está presente na poética de Ana Marques Gastão, a arte da escrita é o seu domínio. Nesse processo poético, que parte do pensamento, uma vez que "o queixo ajuda a mão" (GASTÃO, 2013, p. 17), como na conhecida escultura "Le penseur", de Auguste Rodin, a escrita faz-se nesse movimento do pensamento à ação, movência sobre o papel, esse sobre o qual "a mão é rotura das palavras” (GASTÃO, 2013, p. 17). Contudo, não é só a mão que continuamente se move nesse processo de escrita. Também o corpo se disciplina, se concentra, se desdobra sobre as mãos, numa imagem retesada, como a que nos oferece a poeta no referido ensaio "A cabeça, o corpo, a viagem": "Dobrando o pescoço para a frente, o escritor esgueira-se para fora de si e, movendo as mãos à semelhança de um insecto de asas ágeis e garras tarsais pectinadas, vai escrevendo a partir da dor do movimento ou da sua contradição, limitado por leis desconhecidas" (GASTÃO, 2013, p. 17).

Graça Capinha, no ensaio "O inacabado nascimento ou o excesso mínimo da poesia de Ana Marques Gastão", já havia observado a forte presença das mãos, que no livro Nós/Nudos são "imagem por demais recorrente" (CAPINHA, 2020, p. 455). Observa ainda que as mãos figuram amiudamente em Lápis Mínimo, como metáfora do fazer poético:
[...] e, de novo, são as mãos que obsessivamente regressam. Essas mãos, que se transformam em Deleuze-guattarianos (2004) "lápis desejantes" (Gastão, 2008: 106), que parecem criados exclusivamente para desejar, mãos e lápis mínimos e exaustos para representar o Absoluto e/ou sobre ele algo (CAPINHA, 2020, p. 460).

No primeiro livro de poemas, Tempo para Morrer / Tempo para Viver (1998), encontramse as mãos como imagem ritualizada, como em "Leopardo branco": "Deitamo-nos contra o medo / como se, bafejado pelo mar, / teu corpo trouxesse o Verão / quando na mão levas / o brilho de uma jura / a de escrever à porta de casa / deus somos nós" (GASTÃO, 2003, p. 15). No poema, as mãos são alheias, mas bastante próximas; são as mãos daquele que carrega com cuidado o brilho de uma importante jura, a da instauração de uma nova divindade, mais humana.

Nesse tempo que tece a morte e a vida, sendo essa, a vida, na sequência do título do livro, a etapa final de um tempo tecido, as mãos se prestam ao significativo gesto de encená-la, como que fundando uma realidade mais humana.

No livro seguinte, Terra sem Mãe, as mãos reaparecem com alguma frequência. São elas que ficam para trás, após serem cortadas pelos vidros abertos, na ferida causada pela própria vida, um "bramido inútil" que fere e nos lança corpo, "osso abrasado" para adiante. Na mão repousa o tempo: "Na mão o tempo / oração do osso / a um deus sem olhos" (GASTÃO, 2003, p. 24) ou são elas, as mãos, portadoras da inocência que restaura a calma: "mãos do menino [que] afagam a sombra" (GASTÃO, 2003, p. 25). Ou são ainda a mão metonímica da pátria, tateante dos despojos que restam: "Eis o que resta / da minha pátria. / A mão que procura / sem lógica amargura / o corpo desses mortos" (GASTÃO, 2003, p. 27).

Em outro poema, são elas as mãos de outrem, a quem se pede como uma oração o mundo possível: "Inundas a noite / com tuas mãos / derrama-se por ti / em mim o mundo / agora que és / cavidade absoluta" (GASTÃO, 2003, p. 41). 
Curiosamente, em $O$ silêncio de deus (2001), as mãos não têm presença, nem em forma de oração. Esse silêncio, que reina absoluto, é também a ausência das mãos capazes de promover um encontro tátil, sensível. Deus não tem mãos. Deus é ausente. É o silêncio que instaura não o verbo, mas o alfabeto poético, criação humana e não divina.

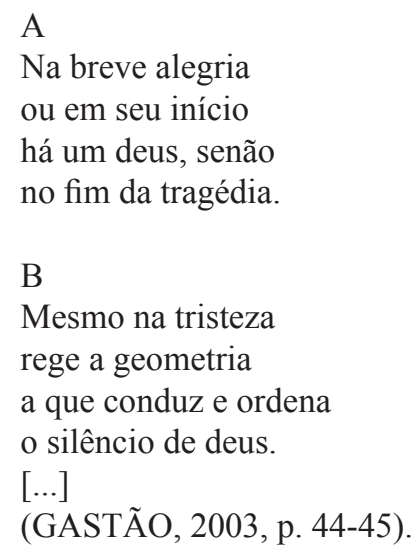

Falto de mãos e de palavras, a ausência de deus, ou o seu silêncio, parece ser o que motiva a poeta a tocar, em suas obras seguintes, a carne do mundo, esse mundo tangível pela mediação do som como em Nocturnos. Canções com palavras (2002) e, posteriormente, em Nós/Nudos (2004) pela mediação de impactantes imagens plásticas, corpóreas, das 25 telas da pintora Paula Rego, com quem estabelece um jogo artístico na sincronicidade das mãos que escrevem (como quem pinta) com as mãos que pintam (como quem escreve); exercício plástico-poético que será retomado mais adiante em $O$ olho e a mão (2018) com o poeta Sérgio Nazar David.

Como se só a arte pudesse devolver as palavras ao homem, também ele emudecido diante do silêncio de deus, a poeta cumpre a humanidade possível, estendendo a mão a outras mãos, igualmente instauradoras de um não silêncio, na contramão de um vazio que, no entanto, persiste.

Em "Nocturno N. ${ }^{\circ}$ 6", as mãos se estendem a um outro, em gesto inaugural que rompe o silêncio, ainda que se negue o coração (por três vezes), e, ao fazê-lo, afirme-o pela negação.
Não é o coração

mas esta carne

em seu rumor.

Não é o coração mas teu silêncio de intenso furor.

Não é o coração mas as mãos sem corpo, vazias.

Na grave melodia de um instante tu e eu em desequilíbrio na infame consistência de um absoluto obstáculo (GASTÃO, 2002, p. 61).

Em Nocturnos, as mãos aparecem com alguma frequência, quase sempre representando as mãos de outrem, daquele com quem a poeta estabelece um contato sutil, como em "Nocturno N. 9":

No pardo céu voam gansos

de asas negras

é o prenúncio da morte.

Não falam de mim os mortos em tuas mãos quando as cidades ruem?

Escuro o tempo, deus esqueceu-se dos seus a não ser no branco sono da casa desabitada (GASTÃO, 2002, p. 77).

Em "Nocturno N. ${ }^{\circ}$ 13", a poeta transforma as mãos em lugar de recolhimento que acolhe o próprio poema: "O poema que te diga / também o amor se perde / e ganha na aridez do dia. / Arrastame pelo espaço / enquanto os outros passam. / Bebe do espírito nas minhas mãos. / Às vezes deita-se nelas como um deus / para logo fugir como um cisne / na paisagem que rodeia a casa" (GASTÃO, 2002, p. 102).

Nesse labor da vida, não deixa de haver a associação entre a mão e a própria escrita, como se vê em "Nocturno N. ${ }^{\circ} 15$ ": 
Sigo o fio da tinta em ríspida página os dedos tacteanto em outro coração.

E rebenta a mão vagarosa no verso síntese do que morre em mim (GASTÃO, 2002, p. 109).

Em Nocturnos, as imagens associadas às mãos também são inúmeras: os dedos, o tocar ou a própria escrita que resulta de seu movimento mãos, como se lê em "Nocturno N. . 19": "Pudesse eu escrever / com as mãos / o olhar que lê / teu poema feito." (GASTÃO, 2002, p. 132). Como um deslizar de dedos ao piano, a poeta traz a imagem das mãos - ora ágeis, ora indagativas, ora vagarosas, ora contemplativas... Mãos que ofertam, mãos que recebem, enquanto a mão da escrita compõe de palavras as canções.

No livro seguinte, Nós/Nudos (2004), encontramos no primeiro poema, "Ajeitando-se", em diálogo com a tela "Grooming", de 1994, de Paula Rego, a imagem das mãos abrindo o poema: "Húmidas, as mãos sustentam um corpo / em si mesmo outro, intrépido, resoluto / na faculdade de expulsão da dor" (GASTÃO, 2004, p. 7).

Se essas mãos sustentam um corpo, há ainda as que estão amputadas, incapazes de sustentar e de se sustentar, como no poema "Sit", em diálogo com a tela de mesmo nome: "Dizer: movo-me, mas não; estou aqui, cérebro colado / aos pés como uma Polaroid translúcida. / Partiram-se as mãos e a cabeça jaz esquartejada no espelho" (GASTÃO, 2004, p. 15).

Em diálogo com a expressiva tela "Come to me” (2002), lemos no poema de mesmo nome já na primeira estrofe: "Hoje vejo-me inteira / poiso os pés / na fenda do mundo / a mão / regressa ao corpo / e chama-te / para dentro do prazer" (GASTÃO, 2002, p. 43). Em "Obediência", em consonância com a tela "Obedience" (2000) de Paula Rego, diz a poeta:

Manipulo a experiência quando sinto o corpo silábico, astuto. / Dissolvo-me, contraio-me, debruço-me sobre a animosidade, / ajoelho, digo sim: consentir é uma dinâmica de recusa. / Meus olhos são dois buracos negros num sarcófago, mas as mãos / amachucam, furtivas, as palavras obstinadas que me levam a ti (GASTÃO, 2004, p. 67).

Outro singularíssimo poema desse livro é "Up the tree", em diálogo com a tela de 2002, de Rego, de mesmo nome. É um poema sobre o poeta e seu voo alegórico. Diz a poeta:

$[\ldots]$
Enfermo de si próprio
o poeta
profetiza a catástrofe
é um subversivo
do delírio
ave do desespero.
Sobre a sua mão
desfeita
anda tão tão devagar
ou então veloz
brinca
com o irremediável
(GASTÃO, 2004, p. 99).

Em Lápis Mínimo (2008), as mãos são artífices da escrita, mas não só. Por vezes, a imagem da mão é metáfora da própria palavra: “[...] A palavra fez-se para intensificar. Rósea raiz, a palavra é olho, ouvido, mão, medida desmedida. Por isso escrevo alto" (GASTÃO, 2008, p. 15).

A mão remete ainda para a ausência e o amparo próprio diante da materialidade do desejo, que se percebe profundo: "Passou a noite a observar as mãos, pálidas. As mesmas mãos que amparam lágrimas, afagam no escuro. Nada tem a cor do desejo profundo" (GASTÃO, 2008, p. 49). Novamente a ausência entra em cena no fragmento: "A falta é o acidente do desejo. Dele faço um tear. As minhas mãos, as mãos, arcaicas mãos, vão morrer sabendo que estão morrendo" (GASTÃO, 2008, p. 53). Contudo, as mãos antigas, arcaicas, nem aqui se mostram estáticas, ao contrário, fazem do acidente do desejo um tear, construindo o tecido do tempo.

Em outra passagem sob a inscrição do ‘desejo', uma das partes de Lápis Mínimo (2008), 
as mãos são o movimento em direção ao outro, a quem o desejo se dirige, e que, em epifania, faz nascer a palavra: "Estendo a mão esquerda: o que sobre de mim ainda te dou. Agora a direita: tento entenderte no antes e logo no depois, Estendo as duas: quase alcanço uma superfície divina. Nesse quasenada nasce a palavra" (GASTÃO, 2008, p. 55).

Não só o desejo, mas o 'amor', outra parte de Lápis Mínimo (2008), associa irremediavelmente amor e escrita: "Um amor deslumbrante, febril, glorioso, castigado: deixamos de conhecer quem conhecemos e a escrita passa a ser não uma mão, mas duas, vazias" (GASTÃO, 2008, p. 59).

Em Adornos (2011), as mãos são mais uma vez suportes necessário ao pensamento no poema intitulado "Degrau":

\author{
Subo um degrau, \\ não de madeira, \\ em terra esquiva. \\ O pé pede repouso \\ e ouso \\ um passo a mais. \\ Mais dois passos \\ e seria \\ o paraíso, \\ a raiz do suplício. \\ Sorrio, áspera, \\ e penso \\ com as mãos: \\ a vida é um sopro \\ invertebrado, \\ tafetá ou monstro \\ (GASTÃO, 2011, p. 28).
}

Presente em outros tantos poemas de Adornos, a imagem da(s) mão(s) aparece ainda associada ao outro, capaz de oferecer a vida, num gesto sutil, como no poema "Aroma suspenso": "O ligeiro deslocar / de tua mão que deste / arbusto retira o aroma, / almiscarado ou floral, / e mo oferece, intacto / é o mais subtil, glorioso / dos movimentos [...]" (GASTÃO, 2011, p. 58).

Em $O$ olho e a mão, Gastão e David tecem cada um o seu poema sobre cada uma das telas significativamente selecionadas, num processo criativo que vai para além da imagem. Como observa Dal Farra:

[...] o quadro é o convite hostil que nos acena com o erro do acerto. Postamo-nos diante dele para produzirmos mais enigmas do que supõe o seu vão hermetismo, para assombrarmos com nossos olhos as suas reverberações. Elucubramos, elegemos (dele) a sombra, botamos em descalabro a sua íntima geometria. Criamos (diante dele e nele) a nossa própria e fervente carne - a nossa língua Também a sua?! (DAL FARRA, 2018).

Diante das imagens-telas-provocação, os poetas pintam com palavras um outro enigma, em que a imagem das mãos é recorrente; o que já se supõe a partir do título do livro. Contudo, as mãos não são somente as da escrita, mas as que se reproduzem nas telas e as que entrelaçam as poesias de ambos os poetas, em diálogo também entre si. Esse traço característico de $O$ olho e a mão mereceria um estudo à parte, mas, no caminho que esse artigo se propõe a seguir, volto à imagem da mão na poesia de Ana Marques Gastão, para destacar, entre tantos, apenas dois poemas. O primeiro deles é "O círculo", que abre junto com "Fera", de Sérgio Nazar David, o diálogo com o quadro "A Chinesa" (1922), de Anita Malfatti. Diz a poeta na estrofe final de "O círculo": "a chinesa é impaciente, fera sem lamento ou / piedade, não dorme, não sossega, as sobrancelhas / desenham o v de vagido, as mãos são de animal / antigo, a chinesa cobre-se mas a provação é a nudez" (GASTÃO; DAVID, 2018, p. 10).

Se as mãos da chinesa são de outra ordem, do não humano, não racional, podendo a qualquer momento promover o gesto descabido de um animal antigo, em "O tigre e eu", poema em diálogo com "Girl with a kitten" (1947), tela de Lucian Freud, novamente as mãos associam-se à ordem do não humano, quando a poeta diz:

Esta não é uma história de amor. Talvez pudesse ser / uma história de amor mas numa história de amor ninguém / passeia assim, imóvel, como um gato de garras agarradas / pelas mãos. Os amantes olham-se nos olhos, vertem / lágrimas 
de cor em pequeninos frascos de pelo espirrado, / possuem-se tão do outro que já não têm de si o suficiente (GASTÃO; DAVID, 2018, p. 44).

Nos dois poemas é exatamente o que não está na ordem do humano que as mãos representam.

Em múltiplas imagens sobre a(s) mão(s), ao longo de alguns dos livros da poeta, buscamos apontar como essa imagem aparece desdobrada em sua poética, sem nunca se esgotar em suas múltiplas significações. Remete-nos, portanto, à própria escrita, que não se reduz, que se reinventa, que pode ser um dos fios do labirinto poético da poesia de Ana Marques Gastão. Voltando ao texto ensaístico 'a cabeça, o corpo, a viagem', destaco, mais uma vez, a imagem da escrita poética em seu árduo e luminoso processo de movimento das mãos com que a poeta termina o ensaio: "Quando suas mãos baixam sobre o papel, ao senti-lo, sabe, pela visão dos dedos, que aquele não é o gosto da morte. [...] Penteia com os dedos as pestanas de um sonho luminoso, sabendo que a neve cansada é fogo gelado" (GASTÃO, 2013, p. 21).

Mãos sobre o papel, mãos que produzem escrita, mãos incansáveis, "arcaicas mãos" (GASTÃO, 2008, p. 53) de fino labor poético; mãos que tecem o fio com que nos convida a entrar no labirinto e dele sair, não igual, nem (in)diferente.

\section{Referências}

BORGES, J. L. El hilo de la fábula. In: BORGES, J. L. Obras completas III. Buenos Aires: Emecê Editores, 2003. p. 477.

CAPINHA, G. O inacabado nascimento ou o excesso mínimo da poesia de Ana Marques Gastão. In: ARNAUT, Ana Paula (Org.). As palavras justas: ensaios sobre literatura e direito. Coimbra: Minerva, 2020. p. 449-464.

DAL FARRA, M. L. [Orelha do livro]. In: GASTÃO, A. M.; DAVID, S. N. O olho e a mão. Rio de Janeiro: 7 Letras, 2018.

GASTÃO, A. M. A definição da noite. São Paulo: Escrituras Editoras, 2003.
GASTÃO, A. M. Adornos. Lisboa: Dom Quixote, 2011.

GASTÃO, A. M. L de Lisboa. Lisboa: Assírio \& Alvim, 2015.

GASTÃO, A. M. Lápis mínimo. Lisboa: Oceanos, 2008.

GASTÃO, A. M. Nocturnos: canções com palavras. Lisboa: Gótica, 2002. n. 10.

GASTÃO, A. M. Nós/Nudos: 25 poemas sobre 25 obras de Paula Rego. Lisboa: Gótica, 2004.

GASTÃO, A. M. As palavras fracturadas: ensaios. Lisboa: Theia Editora, 2013.

GASTÃO, A. M.; DAVID, S. N. O olho e a mão. Rio de Janeiro: 7 Letras, 2018.

PAZ, O. A imagem. In: PAZ, O. Signos em rotação. São Paulo: Perspectiva, 1990. p. 37-50. 
